\title{
Electrospun fibers for vaginal administration of tenofovir disoproxil fumarate and emtricitabine in the context of topical pre-exposure prophylaxis
}

\author{
Rute Nunes $^{\mathrm{a}, \mathrm{b}, \mathrm{c}, 1}$, Sarah Bogas ${ }^{\mathrm{d}, 1}$, Maria João Faria ${ }^{\mathrm{d}}$, Hugo Gonçalves ${ }^{\mathrm{e}}$, Marlene Lúcio ${ }^{\text {d,f, * }}$, \\ Teresa Viseu $^{\mathrm{d}}$, Bruno Sarmento ${ }^{\mathrm{a}, \mathrm{b}, \mathrm{c}}$, José das Neves ${ }^{\mathrm{a}, \mathrm{b}, \mathrm{c}, * *}$ \\ a $i 3 S$ - Instituto de Investigação e Inovação em Saúde, Universidade do Porto, Porto, Portugal \\ ${ }^{\mathrm{b}}$ INEB - Instituto de Engenharia Biomédica, Universidade do Porto, Porto, Portugal \\ ${ }^{\mathrm{c}}$ CESPU, Instituto de Investigação e Formação Avançada em Ciências e Tecnologias da Saúde, Gandra, Portugal

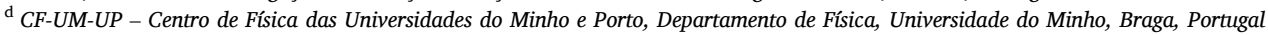 \\ e Paralab, SA, Valbom, Portugal \\ ${ }^{\mathrm{f}}$ CBMA - Centro de Biologia Molecular e Ambiental, Universidade do Minho, Braga, Portugal
}

\section{A R T I C L E I N F O}

\section{Keywords:}

HIV

Liposomes

Microbicides

Polycaprolactone

Poly(vinyl alcohol)

Women's health

\begin{abstract}
A B S T R A C T
Women are particularly vulnerable to sexual HIV-1 transmission. Oral pre-exposure prophylaxis (PrEP) with tenofovir disoproxil fumarate and emtricitabine (TDF/FTC) is highly effective in avoiding new infections in men, but protection has only been shown to be moderate in women. Such differences have been associated, at least partially, to poor drug penetration of the lower female genital tract and the need for strict adherence to continuous daily oral intake of TDF/FTC. On-demand topical microbicide products could help circumvent these limitations. We developed electrospun fibers based on polycaprolactone (PCL fibers) or liposomes associated to poly(vinyl alcohol) (liposomes-in-PVA fibers) for the vaginal co-delivery of TDF and FTC, and assessed their pharmacokinetics in mice. PCL fibers and liposomes-in-PVA fibers were tested for morphological and physicochemical properties using scanning electron microscopy, differential scanning calorimetry and X-ray diffractometry. Fibers featured organoleptic and mechanical properties compatible with their suitable handling and vaginal administration. Fluorescent quenching of mucin in vitro - used as a proxy for mucoadhesion - was intense for PCL fibers, but mild for liposomes-in-PVA fibers. Both fibers were shown safe in vitro and able to rapidly release drug content (15-30 min) under sink conditions. Liposomes-in-PVA fibers allowed increasing genital drug concentrations after a single intravaginal administration when compared to continuous daily treatment for five days with 25-times higher oral doses. For instance, the levels of tenofovir and FTC in vaginal lavage were around 4- and 29-fold higher, respectively. PCL fibers were also superior to oral treatment, although to a minor extent (approximately 2-fold higher drug concentrations in lavage). Vaginal tissue drug levels were generally low for all treatments, while systemic drug exposure was negligible in the case of fibers. These data suggest that proposed fibers may provide an interesting alternative or an ancillary option to oral PrEP in women.
\end{abstract}

\section{Introduction}

Global incidence of HIV infection remains at unacceptably high levels and is unlikely to significantly regress over the next decade [1]. Women in particular are largely vulnerable to sexual transmission due to various biological, behavioral and socio-demographic factors [2].
Protecting women from HIV/AIDS is, therefore, a health imperative. Oral pre-exposure prophylaxis (PrEP) emerged over the last decade as an effective approach to prevent the sexual transmission of HIV-1. Daily oral administration of antiretroviral drugs, namely the combination of tenofovir disoproxil fumarate/emtricitabine (TDF/FTC), has been shown to be highly efficacious in preventing HIV-1 transmission in men

\footnotetext{
* Corresponding author at: CF-UM-UP - Centro de Física das Universidades do Minho e Porto, Departamento de Física, Universidade do Minho, Braga, Portugal.

** Corresponding author at: i3S - Instituto de Investigação e Inovação em Saúde, Universidade do Porto, Porto, Portugal.

E-mail addresses: mlucio@fisica.uminho.pt (M. Lúcio), j.dasneves@i3s.up.pt (J. das Neves).

1 These authors contributed equally to this work
} 
who have sex with men (MSM) [3]. However, outcomes of clinical trials involving heterosexual couples have been mixed regarding the efficacy of oral PrEP in women [4-7]. Adherence to a daily oral regimen has been pointed out as the main cause for failure, but other relevant factors may also be involved [8]. For instance, Cottrell et al. [9] showed that poor drug penetration of the lower female genital tract - particularly in the case of tenofovir (TFV) resulting from the hydrolysis of its prodrug TDF by plasma and tissue esterases - may limit the ability of oral PrEP to protect women. Furthermore, slow onset of protective drug levels and their rapid decline following discontinuation impair the implementation of more flexible regimens such as on-demand regimens that have been successfully introduced in MSM [10]. Typically, 6-7 consecutive daily doses of TDF/FTC are deemed necessary to achieve maximal protection in women [11]. Topical PrEP using vaginal microbicides could help tackle this limitation of oral TDF/FTC in achieving rapid protective drug levels at the genital tract mucosa and potentially allow on-demand use. In particular, the vaginal administration of TDF alone $[12,13]$ or in combination with FTC $[14,15]$ was able to effectively prevent infection in animal models.

Engineering suitable drug delivery platforms is a key step in the microbicide development process. Electrospun polymeric fibers have been proposed for vaginal drug delivery, particularly in the context of HIV-1 prevention, contraception and sexual health [16]. These systems are easy to produce at both the laboratory and industrial scales and are highly versatile. For instance, fibers can simultaneously incorporate different active compounds and be engineered to modulate drug release by using different materials or by changing their architecture [17-19]. Fiber mats can be used similarly to commercially available vaginal films, presenting advantages such as the possibility of self-administration without the need of an applicator, avoidance of extensive leakage typical of semisolid products, or minimal interference with sexual intercourse [20]. Preclinical data suggest that fibers allow achieving quick and extensive coverage of the vaginal epithelium, which could be crucial for providing effective protection from HIV-1 transmission [21]. Furthermore, an exploratory study conducted by performing focus group interviews found that fiber mats are likely to be well accepted by women for topical PrEP [22].

We hypothesize that vaginal TDF/FTC-loaded fibers may be interesting systems for on-demand topical PrEP. Two types of electrospun formulations, each loaded with both drugs and comprising either hydrophobic polycaprolactone (PCL) fibers or a composite of liposomes and hydrophilic poly (vinyl alcohol) (PVA) fibers, were developed. In the case of the composite, we attempted to explore liposomes not only for the purpose of retaining TDF and FTC in fibers, but also for taking advantage of the possible capacity of nanocarriers to improve microbicide drug distribution and retention in the vagina [23]. Both types of fibers were evaluated regarding the ability to provide potentially protective vaginal drug levels, namely by comparing single-dose pharmacokinetics (PK) of fibers to that of continuous use of oral PrEP with TDF/ FTC in a murine model.

\section{Materials and methods}

\subsection{Materials}

TDF was purchased from Kemprotec (Cumbria, UK) and FTC from Sequoia Research Products (Pangbourne, UK). TFV was kindly supplied by Gilead Sciences (Foster City, CA, USA). PCL ( $80 \mathrm{kDa}$ ), sodium lauryl sulfate, purified type II mucin and thiazolyl blue tetrazolium bromide were acquired from Sigma-Aldrich Química (Sintra, Portugal), PVA (57-66 kDa) from Alfa Aesar (Kandel, Germany), and 1,2-dimyristoylsn-glycero-3-phosphocholine (DMPC), 1,2-dioleoyl-sn-glycero-3-phosphoethanolamine (DOPE) and cholesterol (CHL) from Avanti Polar Lipids (INstruchemie, Delfzyl, The Netherlands). Truvada ${ }^{\circledR}$ (Gilead Sciences, Lisbon, Portugal) was acquired from a local pharmacy. All other reagents and solvents were of analytical grade or equivalent.

\subsection{Preparation and characterization of liposomes}

Liposomes were prepared using the thin film hydration technique by modifying a previously reported method [24]. Briefly, DMPC, DOPE and CHL at a molar ratio of 7:2:1 were dissolved in chloroform and the resulting solution was evaporated at $37^{\circ} \mathrm{C}$ under a constant stream of nitrogen. The obtained film was hydrated with ultrapure water above the lipid main phase transition temperature and containing $40 \mu \mathrm{M}$ of TDF and $28 \mu \mathrm{M}$ of FTC. The lipid suspension was vortexed to produce liposomes with a final concentration of $4 \mathrm{mM}$, which were then sonicated in an ultrasonic bath for one minute. Liposomes were characterized for mean hydrodynamic diameter and zeta potential at $25^{\circ} \mathrm{C}$ using a Zetasizer Nano ZS (Malvern Panalytical, Malvern, UK).

\subsection{Production of fibers}

PCL-based fibers containing TDF/FTC (further referred to as 'PCL fibers') and PVA-based fibers incorporating TDF/FTC-loaded liposomes (further referred to as 'liposomes-in-PVA fibers') were produced by electrospinning. Both polymers were dissolved in suitable solvent systems to a final concentration of 7-10\% $(w / v)$. A mixture of chloroform and methanol (3:2 in volume) at room temperature was used for PCL, while PVA was dissolved in an aqueous dispersion of liposomes at $80^{\circ} \mathrm{C}$. TDF and FTC (or drug-loaded liposomes) were then added to a final concentration of $4.0 \%(w / w)$ and $2.8 \%(w / w)$, respectively. An in-house electrospinning setup composed by a CZE2000 high voltage power supply (Spellman, Hauppauge, NY, USA), a $5 \mathrm{~mL}$ plastic syringe coupled to a blunt-end 22G (PCL fibers) or 19G (PVA fibers) needle, a single syringe pump (KD Scientific, Holliston, MA, USA), and a grounded drum collector rotating at $100 \mathrm{rpm}$ was used to produce fibers. Precursor solutions were pumped at $0.6 \mathrm{~mL} \cdot \mathrm{h}^{-1}$ (PCL) or $0.1 \mathrm{~mL} \cdot \mathrm{h}^{-1}$ (PVA) in the presence of a $15 \mathrm{kV}$ (PCL fibers) or $20 \mathrm{kV}$ (PVA fibers) electrical field and collected at a distance of $11 \mathrm{~cm}$. Resulting fiber mats were dried and maintained in a vacuum desiccator until used. PCL fibers and liposomesin-PVA fibers without drugs, as well as PVA fibers without liposomes and drugs, were similarly obtained by omitting drug and/or liposome incorporation during production.

\subsection{Physicochemical, mechanical and biopharmaceutical characterization of fibers}

The morphology of fibers was analyzed by scanning electron microscopy (SEM) using a Nova NanoSEM 200 (FEI, Hillsboro, OR, USA) at an acceleration voltage of $15 \mathrm{kV}$. Cryogenic fractured samples were sputter coated with gold before analysis. Cross-section diameter values of fibers were determined from acquired images using the Digimizer ${ }^{\circledR}$ software (MedCalc Software, Ostend, Belgium). A minimum of 100 measurements were performed for each fiber type. The apparent porosity percentage $(P \%)$ of fiber mats was estimated from thickness measurements according to the following equation:

$P \%=1-\frac{\rho_{\text {fibers }}}{\rho_{\text {polymer }}} \times 100$

where $\rho_{\text {polymer }}$ is the density of PCL $\left(1.15 \mathrm{~g} \cdot \mathrm{cm}^{-3}\right)$ or PVA $\left(1.26 \mathrm{~g} \cdot \mathrm{cm}^{-3}\right)$ and $\rho_{\text {fibers }}$ is the apparent density of fiber mats obtained by dividing the mass of a sample by its volume.

Thermal transitions and thermodynamic parameters of the fibers were analyzed by differential scanning calorimetry (DSC). Measurements were carried out under nitrogen atmosphere using a DSC 214 Polyma (NETZSCH, Selb, Germany), as previously described [25]. Thermograms were obtained at a heating rate of $10{ }^{\circ} \mathrm{C} \cdot \mathrm{min}^{-1}$ in the range of $0-100{ }^{\circ} \mathrm{C}$ for PCL fibers and $150-250{ }^{\circ} \mathrm{C}$ for liposomes-in-PVA fibers. Thermodynamic parameters were calculated using the Proteus ${ }^{\circledR}$ 7.1 software (NETZSCH).

$\mathrm{X}$-ray diffraction patterns were acquired with the micro-focus wide- 
angle X-ray scattering beam line (MiNaXS) of PETRA III (DESY, Hamburg, Germany) using monochromatic synchrotron X-ray radiation (energy of approximately $15 \mathrm{keV}$ and wavelength in the range of 0.82 $\AA$ ). To observe the complete scattering pattern, a 2D pixel detector PILATUS 1M (Dectris, Baden-Daettwil, Switzerland) was used, with a pixel size of $(172 \times 172) \mu \mathrm{m}^{2}$.

The mechanical properties of fiber mats were studied using an AG-IS universal testing machine (Shimadzu, Kyoto, Japan). Stress-strain tests were carried out with a $10 \mathrm{~N}$ load cell and a deformation speed of 10 $\mathrm{mm} \cdot \mathrm{min}^{-1}$ until rupture of fiber mat samples $(10 \mathrm{~mm}$ in width and 25 $\mathrm{mm}$ in length). Young's modulus ( $E$ ) was estimated by linear fitting of stress-strain profiles for $0-7 \%$ of maximum stress.

Mucoadhesive potential of fibers was assessed by estimating their quenching effect on the intrinsic fluorescence of mucin [24]. Fiber mat samples were immersed in an aqueous mucin dispersion $\left(0.2 \mathrm{mg} \cdot \mathrm{mL}^{-1}\right)$ for $180 \mathrm{~min}$ at $37{ }^{\circ} \mathrm{C}$ and $100 \mathrm{rpm}$. Fluorescence measurements of the mucin suspension before and after contact with fibers were carried out at excitation/emission wavelengths of $270 \mathrm{~nm} / 300-500 \mathrm{~nm}$ using a LS 50B fluorimeter (Perkin Elmer, Waltham, MA, USA).

In vitro release of TDF and FTC from fibers was assessed in lactate buffer ( $\mathrm{pH} 4.5$ ) containing $12 \mathrm{mM}$ sodium lauryl sulfate (micellar medium) in order to allow establishing sink conditions while mimicking the amphiphilic content of the cervicovaginal fluids [26]. Briefly, fiber samples $(3 \times 2 \mathrm{~cm})$ were immersed in $30 \mathrm{~mL}$ of medium and maintained at $37{ }^{\circ} \mathrm{C}$ under shaking conditions $(120 \mathrm{rpm})$. Medium samples $(1 \mathrm{~mL})$ were collected at pre-determined time points and replaced with fresh medium, before being assayed by a UV/Vis spectrophotometric derivative method in the range of $200-400 \mathrm{~nm}$ [27]. In vitro drug release profiles were fitted to commonly used kinetics models (first order, Korsmeyer-Peppas and Gallagher-Corrigan) using Prism ${ }^{\circledR} 5$ software (GraphPad Software, La Jolla, CA, USA).

Cytotoxicity of fibers to two female genital cell lines was assessed using the MTT metabolic activity assay, as previously described [28]. Ca Ski cervical and HEC-1-A endometrial cells (ATCC, Manassas, VA, USA), were maintained in RPMI 1640 medium or McCoy's 5A modified medium, respectively, supplemented in both cases with $10 \%(v / v)$ fetal bovine serum (Biochrom $\mathrm{GmbH}$, Berlin, Germany), $100 \mathrm{U} \cdot \mathrm{mL}^{-1}$ penicillin and $100 \mu \mathrm{g} \cdot \mathrm{mL}^{-1}$ streptomycin (BioWest, Nuaillé, France) under standard conditions $\left(37^{\circ} \mathrm{C}, 5 \% \mathrm{CO}_{2}\right.$ and $\left.95 \% \mathrm{RH}\right)$. Extracts were prepared by immersing fiber samples in culture medium at a mat surface area-to-volume of medium of $1 \mathrm{~cm}^{2} \cdot \mathrm{mL}^{-1}$ during $24 \mathrm{~h}$ at $37^{\circ} \mathrm{C}$. Extracts were added to cells $\left(10^{4}\right.$ per well pre-incubated for $24 \mathrm{~h}$ in 96 -well plates) and allowed to incubate for $24 \mathrm{~h}$. Cells were then washed twice with phosphate buffered saline ( $\mathrm{pH}$ 7.4) before adding MTT at 0.5 $\mathrm{mg} \cdot \mathrm{mL}^{-1}$ in medium and incubating for $4 \mathrm{~h}$ under standard conditions. Formazan crystals were dissolved with DMSO and cell viability was determined by measuring the absorbance at $570 \mathrm{~nm}$. Extracts of $1 \%(w /$ $v$ ) Triton ${ }^{\circledR}$ X-100 and plain media were used as controls. Also, extracts of a commercial contraceptive film containing $28 \%$ nonoxynol-9 (VCF®) Vaginal Contraceptive Film, Apothecus, Oyster Bay, NY, USA) were tested for comparison purposes.

\subsection{Pharmacokinetics of TDF/FTC-loaded fibers}

The concentrations of TDF, TFV and FTC in vaginal lavage and tissue, as well as blood plasma, were determined between $15 \mathrm{~min}$ and $24 \mathrm{~h}$ after either intravaginal administration of fibers containing TDF/FTC or oral administration of the drug combinations to 8-12 weeks old female ICR mice. All procedures and experiments were performed using mice bred at the i3S animal facility, approved by the Ethics Committee at IUCSCESPU (process no. 01/ORBEACESPU/2014) and conducted under the European Directive 2010/63/EU guidance, as previously detailed $[29,30]$. Mice were pre-treated subcutaneously with $3 \mathrm{mg}$ of medroxyprogesterone (Depo-Provera ${ }^{\circledR}$, Pfizer, Porto Salvo, Portugal) at seven and three days before administration of TDF/FTC in order to induce a diestrus-like state. Square-shaped fiber mats with approximately 20-25 $\mathrm{mm}^{2}$ and containing of $0.07 \mathrm{mg}$ of TDF and $0.05 \mathrm{mg}$ of FTC were folded in half and administered intravaginally to conscious animals with the aid of tweezers [30]. Oral gavage of TDF/FTC to conscious mice was conducted after pulverization and dispersion of Truvada ${ }^{\circledR}$ tablets in water. Five daily administrations of TDF $\left(62 \mathrm{mg} \cdot \mathrm{kg}^{-1}\right)$ and FTC (41 $\mathrm{mg} \cdot \mathrm{kg}^{-1}$ ) were performed. Animals were allowed to move freely throughout all experiments, with free access to water and food.

After a single intravaginal administration of fibers or following the fifth oral administration of TDF/FTC, mice were euthanized at predetermined time points ( $15 \mathrm{~min}, 1 \mathrm{~h}, 4 \mathrm{~h}$ and $24 \mathrm{~h}$ ) by inhalational isoflurane overdose, followed by intracardiac exsanguination. Blood was collected into Vacuette ${ }^{\circledR}$ tubes with $\mathrm{K}_{3}$ EDTA (Greiner Bio-One, Kremsmünter, Austria) and plasma was recovered by centrifugation $(1180 \times g$, $10 \mathrm{~min}$ ) at $4{ }^{\circ} \mathrm{C}$. The vagina was washed four times with $50 \mu \mathrm{L}$ of normal saline using a micropipette, and the full recovered fluid centrifuged $(13,414 \times g, 10 \mathrm{~min})$ at $4{ }^{\circ} \mathrm{C}$ before collection of supernatant (lavage). Upon necropsy, the vagina was dissected and cut open along its longest axis. Visible residues of fibers were removed in the case of animals treated intravaginally before tissue collection. All samples (plasma, lavage and tissue) were stored at $-80^{\circ} \mathrm{C}$ until further processing. Drug assay was conducted by liquid chromatography-tandem mass spectrometry (LC-MS/MS), as detailed in Supporting Information (S1. Supporting Methods). Data were used to determine: (i) the maximum observed concentration $\left(C_{\max }\right)$ and time at which it occurred $\left(t_{\max }\right)$; (ii) the area-under-the-curve between $15 \mathrm{~min}$ and $24 \mathrm{~h}\left(\mathrm{AUC}_{0.25-24 \mathrm{~h}}\right)$, as calculated by the trapezoidal rule using Prism ${ }^{\circledR} 5$ software; and (iii) the relative bioavailability $\left(F_{\text {rel }}\right)$, defined as the ratio between $\mathrm{AUC}_{0.25-24 \mathrm{~h}}$ values obtained for fibers and oral TDF/FTC, without dose adjustment. Groups of five animals were used per treatment and time point.

\subsection{Statistical analysis}

Experiments were performed in triplicate unless otherwise noted. Data are presented as mean \pm standard deviation (SD), except in the case of PK results for which error is expressed as the standard error of the mean (s.e.m.). Multiple group comparisons were performed by one-way ANOVA with Tukey's HSD post-hoc using Prism ${ }^{\circledR} 5$ software. Values of $p<0.05$ were assumed as denoting significant differences.

\section{Results and discussion}

\subsection{Physicochemical and mechanical characterization of TDF/FTC- loaded fibers}

Both types of TDF/FTC-loaded fibers were successfully produced by electrospinning. Drug-loaded liposomes featuring diameter of $211 \pm 24$ $\mathrm{nm}$ and zeta potential of $-0.67 \pm 0.01 \mathrm{mV}$ were incorporated into PVA fibers. Liposomes-in-PVA and PCL fibers weighted $2.32 \pm 0.73 \mathrm{mg} \cdot \mathrm{cm}^{-2}$ and $4.12 \pm 0.23 \mathrm{mg} \cdot \mathrm{cm}^{-2}$, respectively. Drug content of liposomes-inPVA fibers was $0.28 \mathrm{mg} \cdot \mathrm{cm}^{-2}$ (or $0.12 \mathrm{mg} \cdot \mathrm{mg}^{-1}$ of fibers) in TDF and $0.20 \mathrm{mg} \cdot \mathrm{cm}^{-2}$ (or $0.086 \mathrm{mg} \cdot \mathrm{mg}^{-1}$ of fibers) in FTC, while PCL fibers contained $0.34 \mathrm{mg} \cdot \mathrm{cm}^{-2}$ (or $0.083 \mathrm{mg} \cdot \mathrm{mg}^{-1}$ of fibers) of TDF and 0.24 $\mathrm{mg} \cdot \mathrm{cm}^{-2}$ (or $0.058 \mathrm{mg} \cdot \mathrm{mg}^{-1}$ of fibers) of FTC. PCL and liposomes-inPVA fiber meshes were glossy or pale white, respectively, homogeneous, and soft to the touch (Supporting Information, Fig. S1). Thickness of PCL and liposomes-in-PVA fiber mats was $364 \pm 2.74 \mu \mathrm{m}$ and $133 \pm$ $4.67 \mu \mathrm{m}$, respectively, while $P \%$ was similar in both cases and estimated at $88-90 \%$ (Supporting Information, Fig. S1). SEM imaging revealed that both types of fibers were continuous and had a smooth surface (Fig. 1A). Values for cross-section diameter of PCL fibers and liposomes-in-PVA fibers containing TDF and FTC were $726 \pm 279 \mathrm{~nm}$ and $222 \pm 86 \mathrm{~nm}$, respectively. PCL fibers were not only thicker, but also more heterogeneous in size distribution (Fig. 1B). The incorporation of drugs and drugloaded liposomes was shown to substantially modify the appearance of both types of fibers. PCL fibers without TDF and FTC were roughly $20 \%$ thinner $(591 \pm 191 \mathrm{~nm})$ than drug-loaded counterparts (Supporting 
A

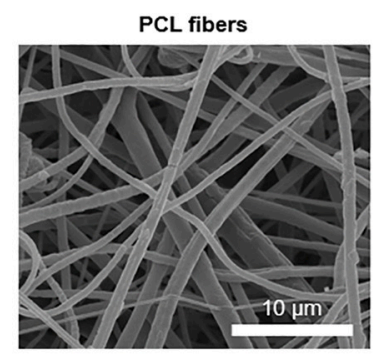

Liposomes-in-PVA fibers
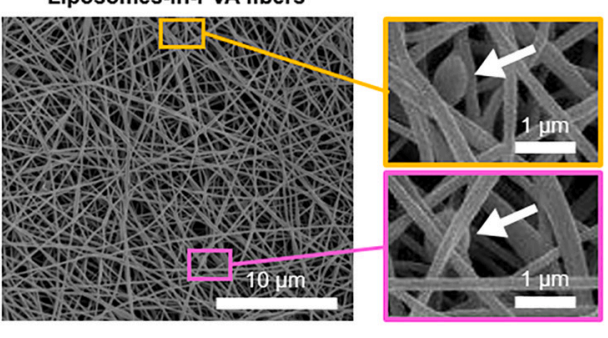

B

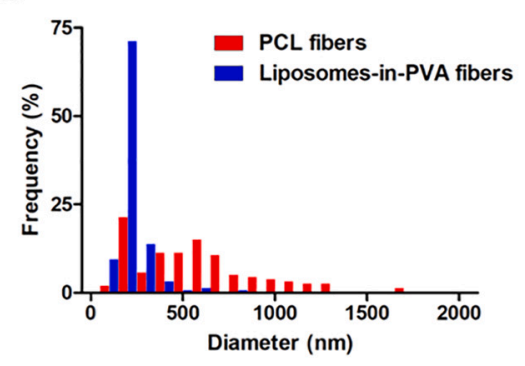

C

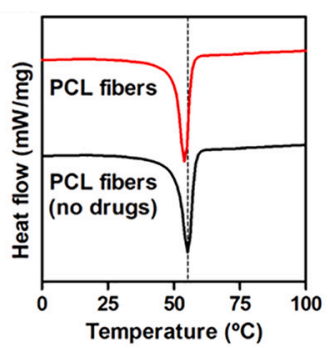

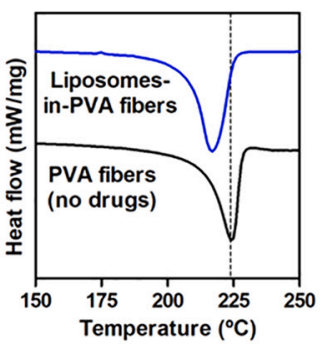

D

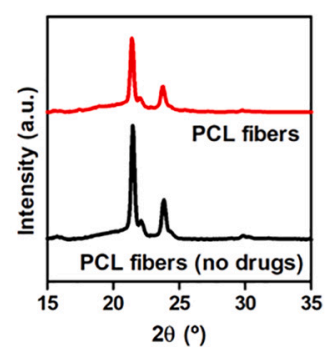

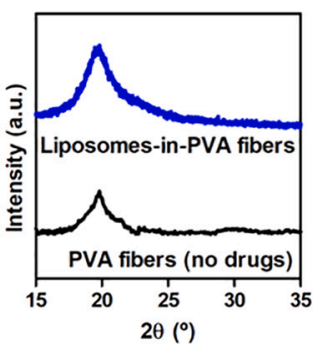

E

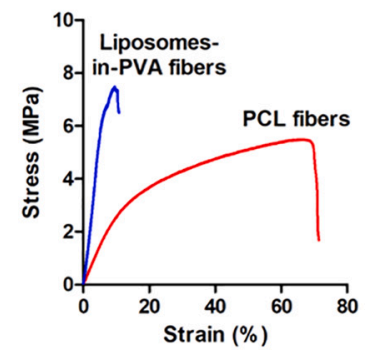

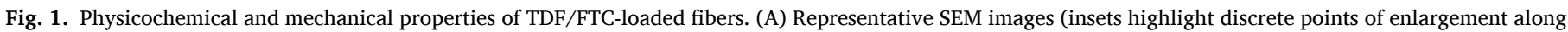

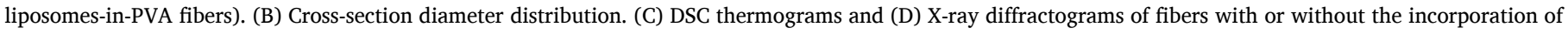

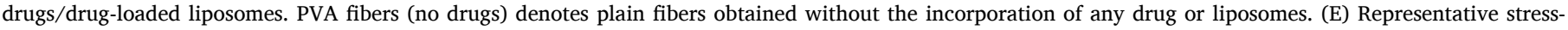
strain curves.

Information, Fig. S2). PCL $(\log \mathrm{P}=4.03)$ is highly lipophilic and unable to dissolve moderately lipophilic/hydrophilic drugs, such as TDF $(\log \mathrm{P}=$ $1.25)$ and FTC $(\log P=-0.43)$. This may dictate the disruption of PCL crystalline domains with consequent fiber enlargement. Conversely, PVA without TDF/FTC-loaded liposomes featured larger a cross-section diameter value of $460 \pm 118 \mathrm{~nm}$ (Supporting Information, Fig. S2). PVA $(\log \mathrm{P}=0.26)$ is not only able to molecularly disperse TDF and FTC, but the incorporation of liposomes may also have led to better polymeric alignment and consequent decrease in fiber diameter. Interestingly, drug-loaded liposomes-in-PVA fibers featured distinctive points of enlargement (roundish bulges), possibly due to the presence of agglomerated liposomes (Fig. 1A). This effect has been previously reported by others [31] and was particularly noticeable in the case of liposomes-in-PVA fibers without drugs (Supporting Information, Fig. S2). The reduced amount of enlarged points in drug-loaded liposomes-inPVA fibers may be related to the ability of the active compounds (especially FTC) to disturb lipid packing [24], thus making liposomes possibly more flexible and featuring less roundish bulges.

DSC analysis was conducted in order to infer the compatibility of fiber ingredients and to analyze the effect of drugs/liposomes on fiber structure. Thermograms underscore the dominance of PCL or PVA, namely by featuring single endothermal peaks resulting from polymer fusion (Fig. 1C). Melting temperature ( $\left.T_{\mathrm{m}}\right)$ values and correspondent enthalpy change $(\Delta H)$ are presented in Table 1 and overlap typical values for PCL or PVA [32,33]. Still, mild reduction of $T_{\mathrm{m}}$ and $\Delta H$ were observed for PCL-based fibers upon drug incorporation, corresponding to a $5 \%$ loss in crystallinity. This suggests lesser fiber stiffness when drugs are present, which is consistent with the different lipophilicity of drugs and polymer. Thermograms of liposomes-in-PVA fibers did not feature typical melting endotherms of drugs (TDF at $115^{\circ} \mathrm{C}$ [34] and FTC $180^{\circ} \mathrm{C}$ [35]) or lipids, thus suggesting good miscibility/incorporation of drugs and liposomes in the polymeric matrix. However, a small reduction in $T_{\mathrm{m}}$ was observed upon drug/liposome addition, which was accompanied by a marked increase in the crystallinity of the polymeric matrix. This appears to indicate that liposomes favored the homogeneous distribution of drugs in PVA fibers, as well as their compatibility.

We next tested fibers by X-ray diffraction in order to confirm
Table 1

Thermodynamic parameters and mechanical properties of fibers, as evaluated by DSC and tensile stress tests. Results for mechanical properties are presented as mean \pm SD $(n=3)$.

\begin{tabular}{|c|c|c|c|c|c|c|}
\hline \multirow[t]{2}{*}{ Fibers } & \multicolumn{3}{|c|}{ Thermodynamic parameters } & \multicolumn{3}{|c|}{ Mechanical properties } \\
\hline & $\begin{array}{l}T_{\mathrm{m}} \\
\left({ }^{\circ} \mathrm{C}\right)\end{array}$ & $\begin{array}{l}\Delta H \\
\left(\mathrm{~J} \cdot \mathrm{g}^{-1}\right)\end{array}$ & $\begin{array}{l}\Delta \text { Crys } \\
(\%)\end{array}$ & $\begin{array}{l}T S_{\max } \\
(\mathrm{MPa})\end{array}$ & $\varepsilon(\%)$ & $\begin{array}{l}E \\
\text { (MPa) }\end{array}$ \\
\hline $\begin{array}{l}\text { PCL fibers (no } \\
\text { drugs) }\end{array}$ & 55.2 & 51.3 & - & $\begin{array}{l}12.8 \pm \\
0.8\end{array}$ & $\begin{array}{l}99.8 \\
\pm 9.2\end{array}$ & $\begin{array}{l}41.3 \pm \\
0.4\end{array}$ \\
\hline PCL fibers & 54.0 & 48.5 & -5 & $\begin{array}{l}5.5 \pm \\
0.1\end{array}$ & $\begin{array}{l}67.8 \\
\pm 9.0\end{array}$ & $\begin{array}{l}28.9 \pm \\
0.3\end{array}$ \\
\hline $\begin{array}{l}\text { PVA fibers (no } \\
\text { drugs) (a) }\end{array}$ & 225.0 & 50.5 & - & $\begin{array}{l}9.5 \pm \\
1.5\end{array}$ & $\begin{array}{l}11.2 \\
\pm 1.2\end{array}$ & $\begin{array}{l}64.2 \pm \\
0.6\end{array}$ \\
\hline $\begin{array}{l}\text { Liposomes-in- } \\
\text { PVA fibers }\end{array}$ & 216.9 & 75.2 & +49 & $\begin{array}{l}7.3 \pm \\
1.2\end{array}$ & $\begin{array}{l}10.3 \\
\pm 1.5\end{array}$ & $\begin{array}{l}86.6 \pm \\
0.8\end{array}$ \\
\hline
\end{tabular}

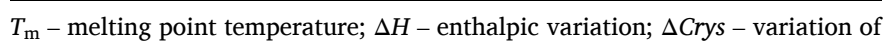
crystalline structure (calculated as $\Delta$ Crys $=100 \times \Delta H_{\text {fibers with drugs }} / \Delta H_{\text {fibers }}$ without drugs); $T S_{\max }$ - Maximum tensile strength at break; $\varepsilon$ - elongation at break; $E$ - Young's modulus. ${ }^{\text {(a) }}$ PVA fibers (no drugs) denotes plain fibers obtained without the incorporation of any drug or liposomes.

crystallinity changes inferred from DSC data. Diffractograms are shown in Fig. 1D. PCL fibers featured two diffraction peaks at $2 \theta=21.4^{\circ}$ and $2 \theta$ $=23.8^{\circ}$ corresponding to the reflections according to the planes $(110,200)$, respectively [36,37]. Both are indicative of the distinctive orthorhombic crystal lattice of the polymer, being only slightly decreased when TDF/FTC were incorporated. This mild loss of the crystallinity of PCL is in agreement with DSC results. In the case of PVAbased fibers, diffractograms were dominated by a characteristic peak at $2 \theta=19.3^{\circ}[38]$. The higher intensity of this peak after the incorporation of TDF/FTC-loaded liposomes supports an increase in crystallinity of fibers and confirms DSC results.

Changes in crystallinity due the incorporation of drugs/liposomes are deemed acceptable as long as they do not compromise the mechanical resistance and structural integrity of mats. Therefore, we performed uniaxial tensile tests (Fig. 1E) and calculated parameters such as elongation $(\varepsilon)$ and tensile strength $\left(T S_{\max }\right)$ at break, as well as elastic 
modulus (Young's modulus; $E$ ), in order to evaluate the mechanical properties of fibers. Considerable differences were observed when drugs/liposomes were present or not (Table 1 and Supporting Information, Fig. S3). Variations in crystallinity were positively correlated with values of $E$ for both types of fibers. PCL fiber mats containing drugs demonstrated a reasonable balance between flexibility and hardness, being able to withstand over $50 \%$ extensional strain. PVA-based fiber mats were less flexible (lower $\varepsilon$ values) than PCL fibers, but the incorporation of TDF/FTC-loaded liposomes did not affect this feature. From a practical point of view, both types of fiber mats could be considered as resistant to relevant handling (e.g., occurring during manufacturing, transport or administration), namely when compared to vaginal films designed for use as microbicides ( $E=5.4-7.8 \mathrm{MPa}[39])$.

\subsection{Biopharmaceutical properties of TDF/FTC-loaded fibers}

The ability of a drug delivery system to associate with mucin at the nanoscale provides a valuable indicator of its putative mucoadhesive properties [40]. We assessed the capacity of fibers to quench the intrinsic fluorescence of mucin by establishing hydrophobic interactions with tryptophan residues. PCL-based fibers were able to reduce fluorescence intensity (Fig. 2A), thus suggesting strong binding to mucin. The quenching effect was particularly pronounced for fibers containing TDF/FTC, which was related to the ability of drugs themselves to interact with tryptophan (Supporting Information, Fig. S4). Additional SEM imaging indicated that mucin was able to intimately coat PCLbased fibers, while X-ray diffraction experiments showed decreased intensity in typical peaks of this type of fibers when mucin was present (Supporting Information, Fig. S4). Altogether, these results suggest that PCL fibers are mucoadhesive due to hydrophobic bonding to mucin [41,42]. Conversely, liposomes-in-PVA fibers did not appear to interact with mucin, except when TDF/FTC were included (Fig. 2A). Results from fluorescence quenching experiments were further reinforced by results of X-ray diffraction patterns for PVA-based fibers in the presence or absence of mucin (Supporting Information, Fig. S4). This seems to indicate that PVA-based fibers feature low mucoadhesiveness, in apparent contrast with previous literature indicating that the polymer is considered to possess mild mucoadhesiveness [43,44]. Curiously, its use in vaginal film formulations is frequent, but usually in combination with polymers possessing higher mucoadhesive potential [45]. Previous studies testing PVA-based fibers also indicate that this polymer seems to possess relatively low in vitro and in vivo mucoadhesiveness upon electrospinning $[46,47]$. The ability of PVA to interact with mucin is dependent on physicochemical properties and processing, namely on the presence of hydrophobic vinyl acetate units. In fact, PVA presenting higher degree of hydrolysis (75-94\%) - such as the one used in the present study - has been shown to present decreased mucoadhesiveness [48]. We also hypothesize that the availability of vinyl acetate units at the surface of fibers may have also been altered due to possible orientation of such hydrophobic residues towards the inner core of the system, preferentially leaving hydrolyzed fractions of PVA at the interface. For example, this arrangement and fine-tuning of vinyl acetate/vinyl alcohol content has been shown effective in rendering sub-micrometer particles as mucus-diffusive in previous studies [48]. Overall, and assuming the quenching percentage as a quantitative indicator of mucoadhesiveness, PCL fibers were approximately 10-fold more mucoadhesive than liposomes-in-PVA fibers (Supporting Information, Fig. S5). These results, however, should be interpreted with caution. Quenching of the intrinsic fluorescence of mucin mostly assesses hydrophobic interactions [49], which have been estimated as quite relevant in defining the mucoadhesiveness of vaginal formulations [50]. Nevertheless, other types of interactions (e.g., electrostatic and hydrogen bonding) that are important in defining the adhesiveness of hydrophilic polymers may have been underestimated.

Next, we evaluated the ability of fibers to release TDF and FTC in micellar medium at $\mathrm{pH}$ 4.5. Drug release from PCL fibers was fast
A
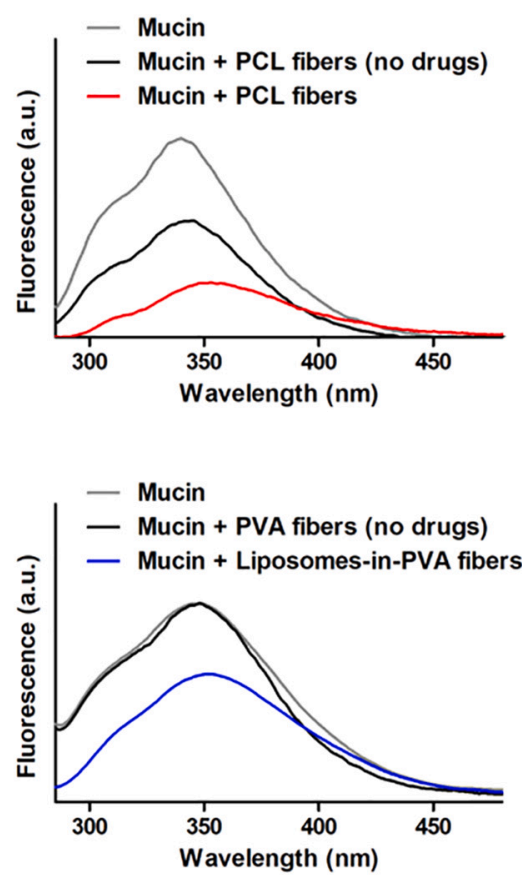

B
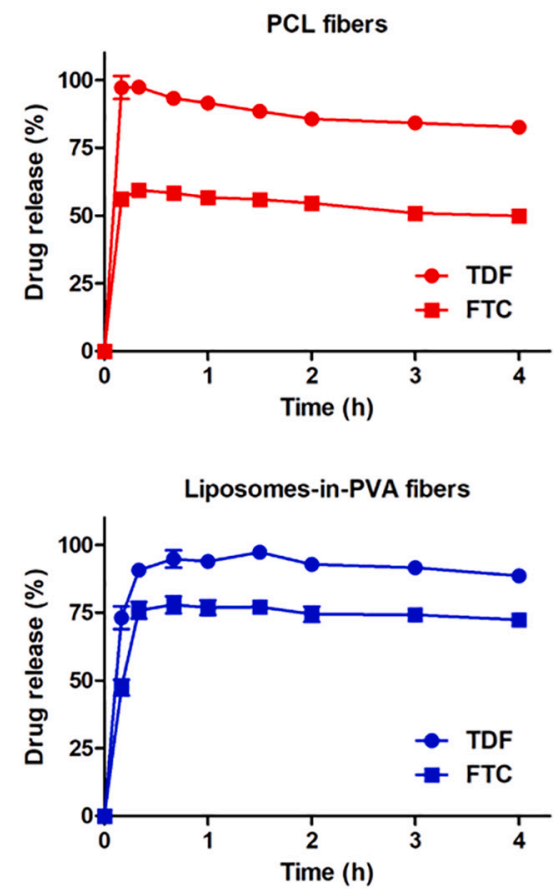

\section{C}

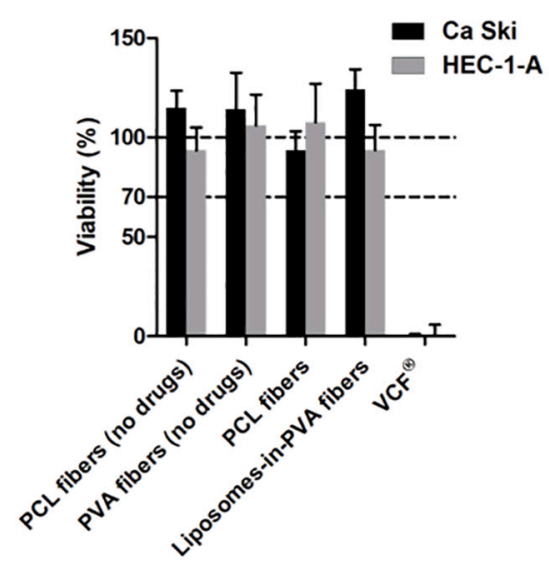

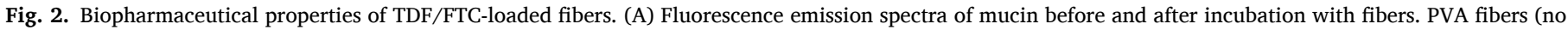

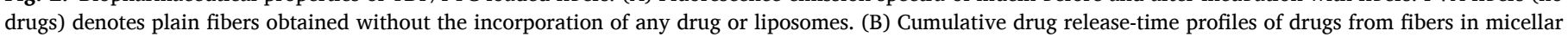

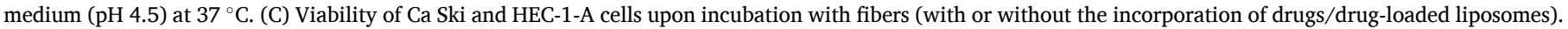
Results in (B) and (C) are presented as mean \pm SD $(n=3)$. 
(within 15-30 min), even if roughly half the amount of FTC was retained up to at least $4 \mathrm{~h}$ (Fig. 2B). While the rapid and complete release of TDF suggests that this drug is located mostly at the surface of the system, the profile of FTC points to a more homogeneous distribution within the PCL matrix [51]. Previous studies showed that TDF typically presents burst release from electrospun fibers composed of hydrophobic polymers such as (poly(lactic-co-glycolic acid) (PLGA), poly(lactide-co-caprolactone), or a 20:80 blend of PCL and PLGA [19,51]. Noticeably, the apparent decrease trend observed in the release profile of TDF from PCL fibers up to $4 \mathrm{~h}$ was likely related with the hydrolysis of the two isopropyloxycarbonyloxymethyl groups of this prodrug in aqueous media, as previously described by Carson and co-workers [19]. Liposomes-inPVA fibers presented similar release profiles to PCL fibers, although the amount of retained FTC was lower (approximately 25\%). This fraction of FTC is likely intimately associated with liposomes as PVAbased fibers are highly soluble and prone to rapidly release payloads. The use of liposomes also seemed to enhance the resistance of TDF to hydrolysis throughout the assay, as apparent for PCL fibers or when the prodrug was directly incorporated into PVA fibers without using liposomes (data not shown). Release profiles of both types of fibers were best fitted to the Gallagher-Corrigan model $\left(R^{2}\right.$ adjusted $\geq 0.979$; Supporting Information, Tables $S 1$ and $S 2$ ), which is indicative of typical biphasic behavior (initial burst followed by slow release) of biodegradable polymeric system [52]. Overall, rapid drug release observed for PCL fibers and liposomes-in-PVA fibers may be considered as beneficial for developing on-demand microbicides, since pericoital administration requires that protective levels of TDF and FTC are achieved in a very short amount of time. Although not explored, fibers developed in this work may still be useful for developing sustained release products, namely by stacking drug-loaded and non-medicated sheets of fiber, as previously proposed by other researchers $[53,54]$.

Lastly, we assessed the toxicity potential of fibers using wellestablished in vitro genital cell models. Extracts of fibers were shown not to be cytotoxic (Fig. 2C). Cell viability was maintained above $90 \%$ for PCL fibers and liposomes-in-PVA fibers - well above the 70\% threshold that is usually considered when testing biomedical materials and devices [55] -,contrasting with the results for VCF® film extracts. These data are in agreement with the recognized safety of PCL and PVA, as well as the relatively low toxicity potential of TDF and FTC. For instance, the maximum concentrations achievable for TDF and FTC in fiber extracts were $140 \mu \mathrm{g} \cdot \mathrm{mL}^{-1}$ and $100 \mu \mathrm{g} \cdot \mathrm{mL}^{-1}$, respectively, which are below the half-maximal cytotoxic concentration $\left(\mathrm{CC}_{50}\right)$ values determined for these drugs in the HeLa cervical cell line $\left(231 \mu \mathrm{g} \cdot \mathrm{mL}^{-1}\right.$ and $>300 \mu \mathrm{g} \cdot \mathrm{mL}^{-1}$, respectively) [28].

\subsection{Pharmacokinetics of TDF/FTC-loaded fibers}

We conducted in vivo experiments in a non-infectious animal model in order to compare local and systemic PK of intravaginally administered fibers with oral TDF/FTC. The vaginal doses of TDF $(0.07 \mathrm{mg})$ and FTC $(0.05 \mathrm{mg})$ were selected in accordance with previous studies demonstrating efficacy in preventing vaginal HIV-1 transmission in humanized mice $[12,15]$. These doses corresponded to the administration of mats with $20 \mathrm{~mm}^{2}(5 \mathrm{~mm} \times 4 \mathrm{~mm})$ for PCL fibers and $25 \mathrm{~mm}^{2}$ (5 $\mathrm{mm} \times 5 \mathrm{~mm}$ ) for liposomes-in-PVA fibers. Truvada ${ }^{\circledR}$ was used in order to better mimic real-world usage of TDF/FTC. Tablets can be crushed and dispersed in water immediately before intake without affecting PK according to information included in the 'Summary of Product Characteristics'. TDF/FTC was administered by gavage at $61.5 \mathrm{mg}$ of TDF and $41 \mathrm{mg}$ of FTC per $\mathrm{kg}$ of body weight (animals weighing about $30 \mathrm{~g}$ ), which correspond to roughly 25 -times the doses administered intravaginally. These were selected by considering the human doses for oral PrEP and back-calculating the amount of each drug for mice using allometric scaling, as defined by the FDA [56]. While the PK of fibers were assessed after a single dose, five daily doses were administered to mice in order to simulate continuous oral PrEP and achieve steady-state drug levels [57].

Drug concentrations - including those of TFV resulting from the hydrolysis of TDF - were determined in vaginal lavage and tissue, as well as in blood plasma, and are presented in Fig. 3. Sampling times were 15 $\min , 1 \mathrm{~h}, 4 \mathrm{~h}$ and $24 \mathrm{~h}$ post-administration, which allow assessing representative short-term, medium-term, long-term and terminal levels of topical microbicides in mice [29,30]. Results for vaginal lavage (Fig. 3A) showed that concentrations of TDF, TFV and FTC were generally higher for liposomes-in-PVA fibers as compared to oral PrEP, particularly at earlier time points, which suggests that these fibers could rapidly provide protective levels upon a single administration. Differences between liposomes-in-PVA fibers and oral TDF/FTC can even be better assessed by comparing values of $\mathrm{AUC}_{0.25-24 \mathrm{~h}}$ (Table 2). For instance, TFV and FTC levels were roughly 4- and 29-times higher, respectively. Differences were also significant for TDF, for which no detectable levels were registered for oral administration. PCL fibers also allowed achieving higher drug concentrations than oral TDF/FTC, although differences were less pronounced. This could be attributable, at least in part, to the poor wettability of hydrophobic fibers and, hence, the inability of the PCL matrix to fully release drugs in the reduced amount of fluids present in the vagina of mice. Indeed, 4 and 3 animals (out of 5) still presented readily identifiable PCL fiber mats at $15 \mathrm{~min}$ and $1 \mathrm{~h}$ post-administration, respectively (Supporting Information, Tables S3). It should also be noted that both TDF and FTC present high enough intrinsic aqueous solubility to assure that the amounts administered to the animals may dissolve in the expectable low amount of mucus present in the vagina [58]. The amount of non-released TDF and FTC could not be assayed since the quantitative collection of residual fibers was unfeasible during necropsy. The capacity of both fibers to allow achieving tangible vaginal levels of TDF (contrasting with nondetectable levels for oral treatment) are particularly relevant due to the enhanced capacity of the prodrug to yield intracellular levels of the active metabolite TFV diphosphate as compared to TFV [59]. Overall, the results for vaginal lavage seem to support that the administration of TDF/FTC-loaded fibers may be able to provide immediate protective concentrations of both drugs that are superior to oral TDF/FTC.

While results for lavage were quite distinct, data analysis for vaginal tissue was hindered by considerable interindividual variability and generally low drug concentrations in samples (Fig. 3B). There was, however, a trend for higher drug levels in the case of oral TDF/FTC, which were significant at $1 \mathrm{~h}$ post-administration in the case of TDF and FTC. This suggests some degree of drug accumulation in tissue resulting from continuous oral use or simply poor mucosal permeation of intravaginally administered drugs. TDF, TFV and FTC are BCS class III compounds and substrates of important efflux transporters such as Pglycoprotein (TDF and TFV), Mrp1 (FTC) or Mrp4 (TFV), which are highly expressed in the cervicovaginal mucosa of mice [60-62]. PK parameters further reinforce the reduced ability of fibers to yield lower drug concentrations in tissue (Table 2). This was particularly apparent for FTC $\left(F_{\text {rel }}=0.02-0.2\right)$, while in the case of TFV or its prodrug, fibers could achieve similar levels of one of these compounds $\left(F_{\text {rel }}(\mathrm{TDF})=0.9\right.$ for liposomes-in-PVA fibers and $F_{\text {rel }}$ (TFV) $=0.5$ for PCL fibers). Noteworthy, TFV levels in vaginal tissue following oral administration were in general agreement with results reported for TDF administered orally to female BALB/c mice $\left(\mathrm{AUC}_{2-24 \mathrm{~h}}=9681 \mathrm{ng} \cdot \mathrm{h} \cdot \mathrm{g}^{-1}\right.$ and $t_{\max }$ between $2 \mathrm{~h}$ and $8 \mathrm{~h}$ ) [57], with variations likely reflecting differences in sample collection time points. In the case of vaginal administration of TDF and FTC, no comparable regional PK data have been previously described.

Data for blood plasma indicate low systemic drug exposure with the use of topical fibers, as denoted by their values of $\mathrm{AUC}_{0.25-24 \mathrm{~h}}$ and $F_{\text {rel }}$ (Table 2). It is worthwhile mentioning that one of the defining advantages of microbicides over oral PrEP relates with the principle of blocking transmission at the mucosal site and abbreviate the onset of possible adverse effects related with high systemic exposure to active payloads [63]. The blood plasma profile obtained for TFV with oral TDF/FTC was consistent with data previously found for the oral 
A

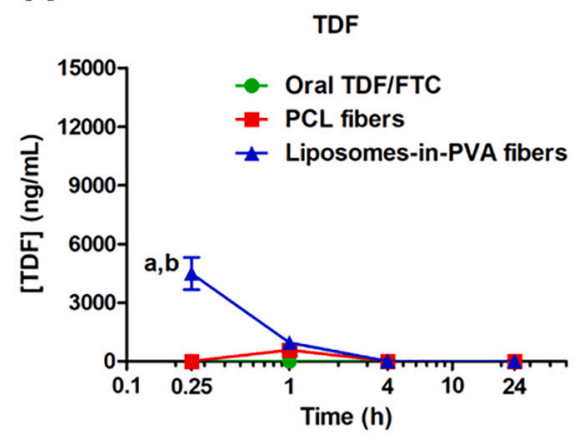

B

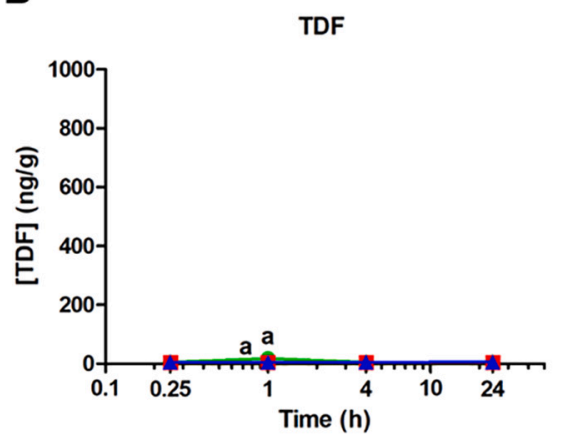

C

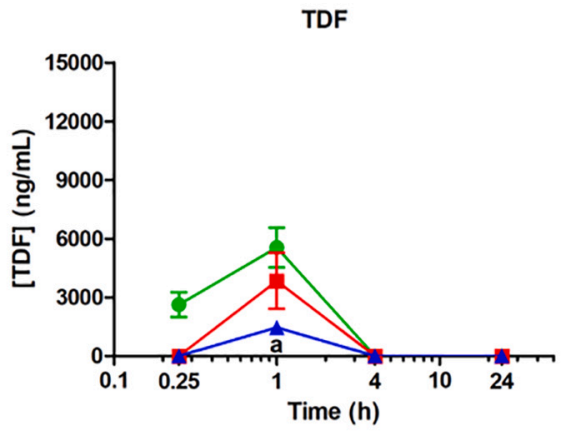

TFV

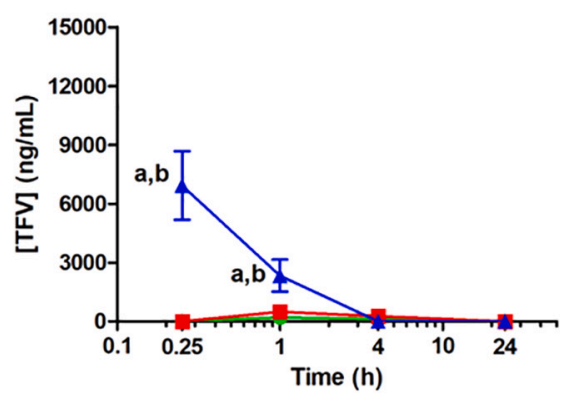

TFV

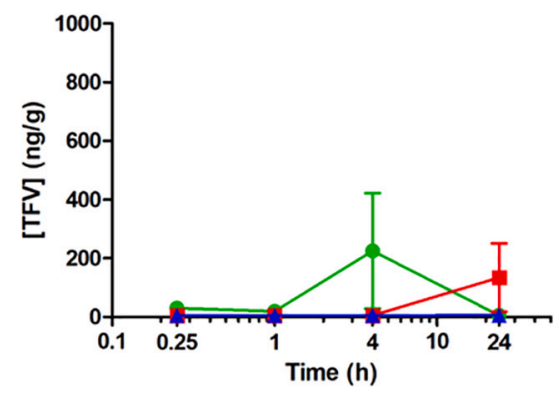

TFV

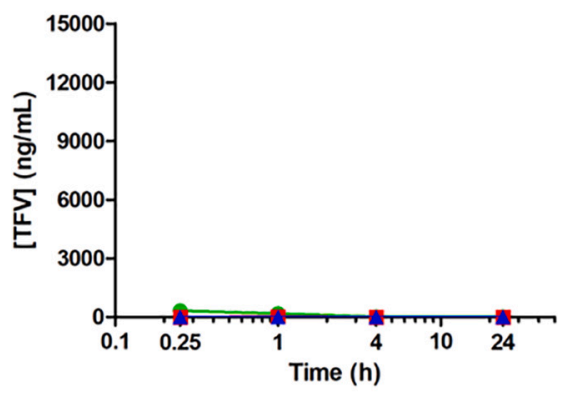

FTC

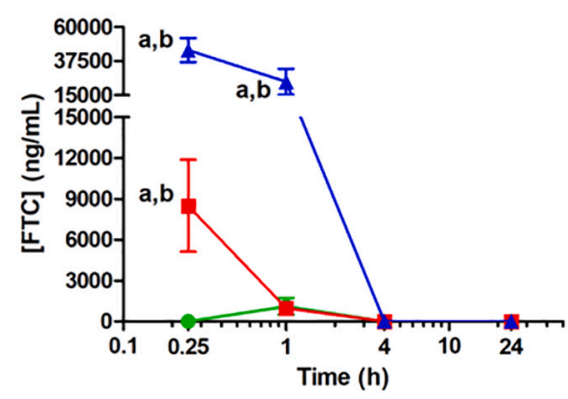

FTC

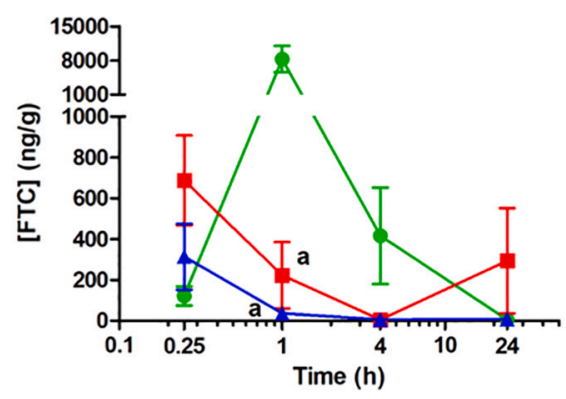

FTC

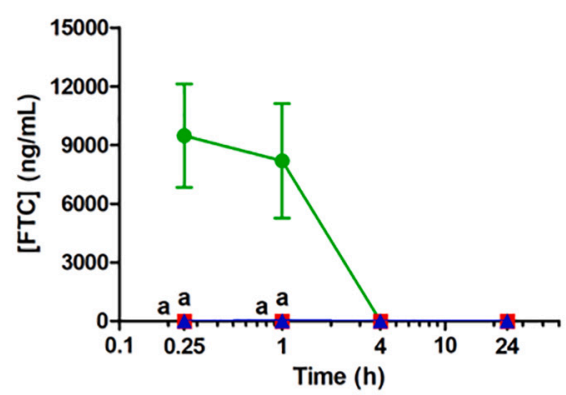

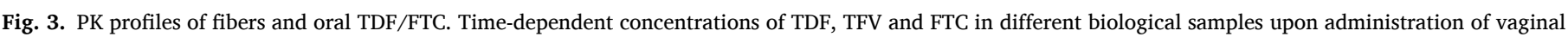

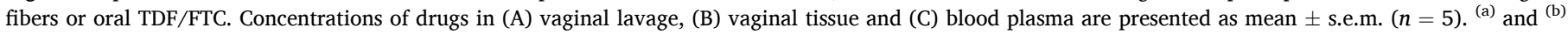
denote statistically significant differences $(p<0.05)$ when comparing with oral TDF/FTC or the other type of fibers, respectively.

administration of TDF to female BALB/c mice, namely concerning the early onset of $C_{\max }[57,64]$. However, AUC values for similar oral doses were widely variable among studies: Veselinovic et al. [57] reported $\mathrm{AUC}_{2-48 \mathrm{~h}}=17,278 \mathrm{ng} \cdot \mathrm{h} \cdot \mathrm{mL}^{-1}\left(12,251 \mathrm{ng} \cdot \mathrm{h} \cdot \mathrm{mL}^{-1}\right.$ when tested in humanized mice), while $\mathrm{Ng}$ et al. [64] reported $\mathrm{AUC}_{0.5-24 \mathrm{~h}}=3984$ $\mathrm{ng} \cdot \mathrm{h} \cdot \mathrm{mL}^{-1}$. Again, these variations probably reflect methodological differences between studies.

Apart from the discussion regarding relative drug levels in different biological samples for considered administration routes and/or fibers, it seems important to infer on how absolute values could translate into protection from HIV-1 transmission. Correlation between regional PK and efficacy for topical TDF/FTC has not yet been fully established. However, data from Gallay et al. [15] suggest that vaginal lavage concentrations of at least $4 \mathrm{ng} / \mathrm{mL}$ for FTC and $500 \mathrm{ng} / \mathrm{mL}$ for TDF (assuming a washing protocol similar to the one used in this work) are associated with full prevention of viral transmission in humanized mice. In our study, mean levels of FTC in lavage between $15 \mathrm{~min}$ and $1 \mathrm{~h}$ postadministration were at least around 6000- and 250-times higher than the previous protective threshold in the case of liposomes-in-PVA fibers and PCL fibers, respectively. As for oral treatment, the concentration of FTC in lavage at $1 \mathrm{~h}$ was considerably above $4 \mathrm{ng} / \mathrm{mL}$, but could not be guaranteed early on following administration. Mean levels of TDF in lavage were also maintained at least 2-times above the threshold reported by Gallay et al. for liposomes-in-PVA fibers between $15 \mathrm{~min}$ and $1 \mathrm{~h}$. This was not the case for PCL fibers at $15 \mathrm{~min}$. TDF in lavage was undetectable in the case of oral administration from $15 \mathrm{~min}$ to $24 \mathrm{~h}$, which could reflect the conversion of the prodrug into TFV by esterases following oral absorption [65]. Furthermore, measurable plasmatic levels of TDF and TFV suggest that these drugs actually have poor ability to concentrate in the vaginal tissue of mice, thus paralleling what has been reported for women [9].

This study presents a few limitations that need to be considered when interpreting its findings. Firstly, PK data discussed in this manuscript reflect the analysis of a limited amount of time points that, nonetheless, typically reflect the dynamics of vaginal microbicide drug delivery in mice, as discussed above. Results from mouse models should also be interpreted carefully, particularly when envisioning a direct translation into the human scenario. Vaginal leakage in mice after topical administration is particularly extensive, and leads to low and rapidly decreasing drug levels. Still, the relevance of mouse models (namely humanized) to the development of PrEP cannot be denied and comparison with gold standard clinical practice, such as represented by oral 
Table 2

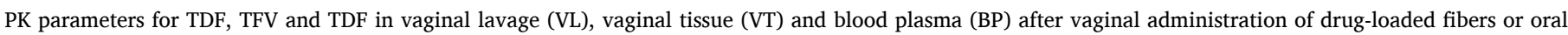
administration of TDF/FTC. Results for $C_{\max }$ and $t_{\max }$ are presented as mean \pm s.e.m. $(n=5)$.

\begin{tabular}{|c|c|c|c|c|c|c|c|c|c|c|c|c|c|}
\hline \multirow[t]{2}{*}{ Drugs } & \multirow[t]{2}{*}{ Formulation } & \multicolumn{3}{|l|}{$C_{\max }\left(\mathrm{ng} \cdot \mathrm{mL}^{-1}\right)^{\mathrm{a}}$} & \multicolumn{3}{|c|}{$t_{\max }(\mathrm{h})$} & \multicolumn{3}{|c|}{$\mathrm{AUC}_{0.25-24 \mathrm{~h}}\left(\mathrm{ng} \cdot \mathrm{h} \cdot \mathrm{mL}^{-1}\right)^{\mathrm{b}}$} & \multicolumn{3}{|l|}{$F_{\text {rel }}$} \\
\hline & & VL & VT & $\mathrm{BP}$ & VL & VT & $\mathrm{BP}$ & VL & VT & $\mathrm{BP}$ & VL & VT & BP \\
\hline \multirow[t]{3}{*}{ TDF } & Oral TDF/FTC & ND & $17.9 \pm 3.6$ & $5550 \pm 1013$ & ND & 1 & 1 & 0 & 142.9 & 11,392 & - & - & - \\
\hline & Vaginal PCL fibers & $584 \pm 103$ & ND & $3848 \pm 1435$ & 1 & ND & 1 & 1096 & ND & 7216 & ND & $\approx 0$ & 0.6 \\
\hline & Vaginal liposomes-in-PVA fibers & $4488 \pm 820$ & $6.2 \pm 0.7$ & $1474 \pm 230$ & 0.25 & 24 & 1 & 3470 & 130.7 & 2763 & ND & 0.9 & 0.2 \\
\hline TFV & Oral TDF/FTC & $205 \pm 72$ & $225 \pm 197$ & $326 \pm 162$ & 1 & 4 & 0.25 & 1763 & 2690 & 818 & - & - & - \\
\hline \multirow[t]{2}{*}{ - } & Vaginal PCL fibers & $492 \pm 64$ & $135 \pm 116$ & $14.8 \pm 4.0$ & 1 & 24 & 1 & 3981 & 1415 & 26.8 & 2.3 & 0.5 & 0.03 \\
\hline & Vaginal liposomes-in-PVA fibers & $6929 \pm 1746$ & $6.2 \pm 0.7$ & $7.4 \pm 3.1$ & 0.25 & 24 & 1 & 6979 & 130.7 & 13.9 & 4.0 & 0.05 & 0.02 \\
\hline \multirow[t]{3}{*}{ FTC } & Oral TDF/FTC & $1115 \pm 618$ & $8301 \pm 236$ & $9475 \pm 2646$ & 1 & 4 & 0.25 & 2091 & 20,447 & 18,917 & - & - & - \\
\hline & Vaginal PCL fibers & $8498 \pm 3377$ & $688 \pm 220$ & ND & 0.25 & 0.25 & ND & 5040 & 3670 & ND & 2.4 & 0.2 & $\approx 0$ \\
\hline & Vaginal liposomes-in-PVA fibers & $44,793 \pm 7944$ & $314 \pm 145$ & $15.5 \pm 15.5$ & 0.25 & 0.25 & 1 & 61,564 & 325 & 29.1 & 29.4 & 0.02 & 0.002 \\
\hline
\end{tabular}

ND - not determined.

a $\mathrm{ng} \cdot \mathrm{g}^{-1}$ for VT.

b $\mathrm{ng} \cdot \mathrm{h} \cdot \mathrm{g}^{-1}$ for vaginal tissue.

administration of Truvada in this study, provides important hints regarding the potential of new preventative strategies [66]. Secondly, we did not evaluate tissue levels of active metabolites of TDF/TFV and FTC, namely TFV diphosphate and FCT triphosphate. However, preclinical (from mice) and clinical data support that genital tract levels of precursor and active forms are fairly correlated, and that vaginal PK profiles of TDF/TFV and FTC can be used to assess the potential for protection against HIV-1 transmission [15,67]. Thirdly, the impact of sexual intercourse on PK was not considered despite being likely considerable. Fourth, the role of liposomes and their association with fibers in enhancing mucosal drug levels was not fully assessed in this work. However, our previous work pinpoints that the association of nanocarriers to polymeric platforms used for vaginal administration, namely rapid-dissolving films, potentiates the local drug retention and distribution [30]. In a related study, Krogstad et al. [47] reported that the incorporation of etravirine-loaded PLGA nanoparticles into PVA fibers provided enhanced vaginal retention of both nanocarrier and the antiretroviral drug over 7 days. Although the outcome of using liposomes-in-PVA fibers was not so remarkable, higher drug levels in vaginal lavage as compared to PCL fibers could be attributed to a similar effect resulting from the administration of a nanocarrier-in-fiber composite. Fourthly, our study was designed only for comparing topical fibers with currently approved oral PrEP with TDF/FTC. Still, it should be acknowledged that other promising topical $[14,68]$ and systemic [69-71] delivery technologies for PrEP are currently being evaluated, and future comparative assessment would be interesting. Finally, formal safety studies were not conducted. Still, the reduced cytotoxicity of fibers, alongside the favorable safety track record of individual materials, seem to backup that PCL fibers and liposomes-in-PVA fibers are potentially safe.

\section{Conclusions}

We produced and characterized two formulations based on polymeric fibers that could be useful for the vaginal delivery of TDF and FTC in the context of topical PrEP. PCL fibers and liposomes-in-PVA fibers were shown to possess adequate biopharmaceutical properties, namely drug release profiles compatible with on-demand microbicide use and low toxicity to cells of the female genital tract. Both types of fibers provided rapid onset of local drug levels upon single vaginal administration to mice, namely when compared to the continuous daily use for five days of oral TDF/FTC. Moreover, drug concentrations in vaginal fluids were moderately sustained up to $1-4 \mathrm{~h}$, which could be translatable into a fairly wide protection time window in humans. This was particularly noticeable for liposomes-in-PVA fibers. The ability of fibers to provide vaginal tissue drug concentrations that were at least as high as those obtained with oral TDF/FTC was not clear and needs further clarification. Overall, the proposed drug-loaded fibers may provide an interesting on-demand alternative or a complementary tool to currently available oral PrEP requiring the daily administration of TDF/FTC.

\section{Data availability}

The data that support the findings of this study are available from the corresponding authors on reasonable request.

\section{CRediT authorship contribution statement}

Rute Nunes: Formal analysis, Investigation, Writing - review \& editing. Sarah Bogas: Formal analysis, Investigation, Writing - review \& editing. Maria João Faria: Formal analysis, Investigation, Writing review \& editing. Hugo Gonçalves: Formal analysis, Investigation, Writing - review \& editing. Marlene Lúcio: Conceptualization, Data curation, Formal analysis, Funding acquisition, Investigation, Methodology, Project administration, Supervision, Writing - original draft. Teresa Viseu: Conceptualization, Data curation, Formal analysis, Funding acquisition, Methodology, Supervision, Writing - review \& editing. Bruno Sarmento: Conceptualization, Formal analysis, Funding acquisition, Methodology, Supervision, Writing - review \& editing. José das Neves: Conceptualization, Data curation, Formal analysis, Funding acquisition, Investigation, Methodology, Project administration, Supervision, Writing - original draft.

\section{Declaration of Competing Interest}

The authors declare no conflict of interest.

\section{Acknowledgements}

This work was financed by Programa Gilead GÉNESE (refs. PGG/ 046/2015) and Portuguese funds through FCT - Fundação para a Ciência e a Tecnologia/Ministério da Ciência, Tecnologia e Ensino Superior in the framework of the project "Institute for Research and Innovation in Health Sciences" UID/BIM/04293/2019. The work was also financed by FCT in the framework of the Strategic Funding UID/FIS/04650/2019 and in the ambit of the project POCI-01-0145-FEDER-032651 and PTDC/NAN-MAT/326512017, co-financed by the FEDER, through COMPETE 2020, under PORTUGAL 2020, and FCT. Marlene Lúcio thanks FCT and ERDF for doctoral position Ref. CTTI-150/18-CF(1) in the ambit of the project CONCERT (POCI-01-0145-FEDER-032651 and PTDC/NAN-MAT/326512017).

\section{Appendix A. Supplementary data}

Supplementary data to this article can be found online at https://doi. org/10.1016/j.jconrel.2021.05.003. 


\section{References}

[1] GBD 2017 HIV collaborators, Global, regional, and national incidence, prevalence, and mortality of HIV, 1980-2017, and forecasts to 2030, for 195 countries and territories: a systematic analysis for the global burden of diseases, injuries, and risk factors study 2017, Lancet HIV 6 (2019) (2017) e831-e859.

[2] A.A. Adimora, C. Ramirez, J.D. Auerbach, S.O. Aral, S. Hodder, G. Wingood, W. EISadr, E.A. Bukusi, H. I. V. Prevention Trials Network Women at Risk Committee, Preventing HIV infection in women, J. Acquir. Immune Defic. Syndr. 63 (Suppl. 2) (2013) S168-S173.

[3] X. Huang, J. Hou, A. Song, X. Liu, X. Yang, J. Xu, J. Zhang, Q. Hu, H. Chen, Y. Chen, K. Meyers, H. Wu, Efficacy and safety of oral TDF-based pre-exposure prophylaxis for men who have sex with men: a systematic review and metaanalysis, Front. Pharmacol. 9 (2018) 799.

[4] J.M. Baeten, D. Donnell, P. Ndase, N.R. Mugo, J.D. Campbell, J. Wangisi, J. W. Tappero, E.A. Bukusi, C.R. Cohen, E. Katabira, A. Ronald, E. Tumwesigye, E. Were, K.H. Fife, J. Kiarie, C. Farquhar, G. John-Stewart, A. Kakia, J. Odoyo, A. Mucunguzi, E. Nakku-Joloba, R. Twesigye, K. Ngure, C. Apaka, H. Tamooh, F. Gabona, A. Mujugira, D. Panteleeff, K.K. Thomas, L. Kidoguchi, M. Krows, J. Revall, S. Morrison, H. Haugen, M. Emmanuel-Ogier, L. Ondrejcek, R. W. Coombs, L. Frenkel, C. Hendrix, N.N. Bumpus, D. Bangsberg, J.E. Haberer, W. S. Stevens, J.R. Lingappa, C. Celum, Antiretroviral prophylaxis for HIV prevention in heterosexual men and women, N. Engl. J. Med. 367 (2012) 399-410.

[5] M.C. Thigpen, P.M. Kebaabetswe, L.A. Paxton, D.K. Smith, C.E. Rose, T. M. Segolodi, F.L. Henderson, S.R. Pathak, F.A. Soud, K.L. Chillag, R. Mutanhaurwa, L.I. Chirwa, M. Kasonde, D. Abebe, E. Buliva, R.J. Gvetadze, S. Johnson, T. Sukalac V.T. Thomas, C. Hart, J.A. Johnson, C.K. Malotte, C.W. Hendrix, J.T. Brooks, Antiretroviral preexposure prophylaxis for heterosexual HIV transmission in Botswana, N. Engl. J. Med. 367 (2012) 423-434.

[6] L. Van Damme, A. Corneli, K. Ahmed, K. Agot, J. Lombaard, S. Kapiga, M. Malahleha, F. Owino, R. Manongi, J. Onyango, L. Temu, M.C. Monedi, P. Mak'Oketch, M. Makanda, I. Reblin, S.E. Makatu, L. Saylor, H. Kiernan, S. Kirkendale, C. Wong, R. Grant, A. Kashuba, K. Nanda, J. Mandala, K. Fransen, J. Deese, T. Crucitti, T.D. Mastro, D. Taylor, Preexposure prophylaxis for HIV infection among African women, N. Engl. J. Med. 367 (2012) 411-422.

[7] J.M. Marrazzo, G. Ramjee, B.A. Richardson, K. Gomez, N. Mgodi, G. Nair, T. Palanee, C. Nakabiito, A. van der Straten, L. Noguchi, C.W. Hendrix, J.Y. Dai, S. Ganesh, B. Mkhize, M. Taljaard, U.M. Parikh, J. Piper, B. Masse, C. Grossman, J. Rooney, J.L. Schwartz, H. Watts, M.A. Marzinke, S.L. Hillier, I.M. McGowan, Z M. Chirenje, VOICE study team, Tenofovir-based preexposure prophylaxis for HIV infection among African women, N. Engl. J. Med. 372 (2015) 509-518.

[8] K.A. Thomson, J.M. Baeten, N.R. Mugo, L.G. Bekker, C.L. Celum, R. Heffron, Tenofovir-based oral preexposure prophylaxis prevents HIV infection among women, Curr. Opin. HIV AIDS 11 (2016) 18-26.

[9] M.L. Cottrell, K.H. Yang, H.M. Prince, C. Sykes, N. White, S. Malone, E.S. Dellon, R. D. Madanick, N.J. Shaheen, M.G. Hudgens, J. Wulff, K.B. Patterson, J.A. Nelson, A. D. Kashuba, A translational pharmacology approach to predicting outcomes of preexposure prophylaxis against HIV in men and women using tenofovir disoproxil fumarate with or without emtricitabine, J. Infect. Dis. 214 (2016) 55-64.

[10] J.M. Molina, C. Capitant, B. Spire, G. Pialoux, L. Cotte, I. Charreau, C. Tremblay, J. M. Le Gall, E. Cua, A. Pasquet, F. Raffi, C. Pintado, C. Chidiac, J. Chas, P. Charbonneau, C. Delaugerre, M. Suzan-Monti, B. Loze, J. Fonsart, G. Peytavin, A. Cheret, J. Timsit, G. Girard, N. Lorente, M. Preau, J.F. Rooney, M.A. Wainberg, D. Thompson, W. Rozenbaum, V. Dore, L. Marchand, M.C. Simon, N. Etien, J. P. Aboulker, L. Meyer, J.F. Delfraissy, A.I.S. Group, On-demand preexposure prophylaxis in men at high risk for HIV-1 infection, N. Engl. J. Med. 373 (2015) 2237-2246.

[11] R.J. Landovitz, Preexposure prophylaxis for HIV prevention: what we know and what we still need to know for implementation, Top. Antivir. Med. 23 (2015) 85-90.

[12] C.J. Destache, S. Mandal, Z. Yuan, G. Kang, A.A. Date, W. Lu, A. Shibata, R. Pham, P. Bruck, M. Rezich, Y. Zhou, R. Vivekanandan, C.V. Fletcher, Q. Li, Topical tenofovir disoproxil fumarate nanoparticles prevent HIV-1 vaginal transmission in a humanized mouse model, Antimicrob. Agents Chemother. 60 (2016) 3633-3639.

[13] J.M. Smith, R. Rastogi, R.S. Teller, P. Srinivasan, P.M. Mesquita, U. Nagaraja, J. M. McNicholl, R.M. Hendry, C.T. Dinh, A. Martin, B.C. Herold, P.F. Kiser, Intravaginal ring eluting tenofovir disoproxil fumarate completely protects macaques from multiple vaginal simian-HIV challenges, Proc. Natl. Acad. Sci. U. S. A. 110 (2013) 16145-16150.

[14] P. Srinivasan, J.A. Moss, M. Gunawardana, S.A. Churchman, F. Yang, C.T. Dinh, J. M. Mitchell, J. Zhang, R. Fanter, C.S. Miller, I. Butkyavichene, J.M. McNicholl, T. J. Smith, M.M. Baum, J.M. Smith, Topical delivery of tenofovir disoproxil fumarate and emtricitabine from pod-intravaginal rings protects macaques from multiple SHIV exposures, PLoS One 11 (2016), e0157061.

[15] P.A. Gallay, U. Chatterji, A. Kirchhoff, A. Gandarilla, M. Gunawardana, R.B. Pyles, M.A. Marzinke, J.A. Moss, M.M. Baum, Prevention of vaginal and rectal HIV transmission by antiretroviral combinations in humanized mice, PLoS One 12 (2017), e0184303.

[16] A.K. Blakney, Y. Jiang, K.A. Woodrow, Application of electrospun fibers for female reproductive health, Drug Deliv. Transl. Res. 7 (2017) 796-804.

[17] C. Huang, S.J. Soenen, E. van Gulck, G. Vanham, J. Rejman, S. Van Calenbergh, C. Vervaet, T. Coenye, H. Verstraelen, M. Temmerman, J. Demeester, S.C. De Smedt, Electrospun cellulose acetate phthalate fibers for semen induced anti-HIV vaginal drug delivery, Biomaterials 33 (2012) 962-969.
[18] C. Ball, S.F. Chou, Y. Jiang, K.A. Woodrow, Coaxially electrospun fiber-based microbicides facilitate broadly tunable release of maraviroc, Mater. Sci. Eng. C 63 (2016) 117-124.

[19] D. Carson, Y. Jiang, K.A. Woodrow, Tunable release of multiclass anti-HIV drugs that are water-soluble and loaded at high drug content in polyester blended electrospun fibers, Pharm. Res. 33 (2016) 125-136.

[20] A.K. Blakney, C. Ball, E.A. Krogstad, K.A. Woodrow, Electrospun fibers for vaginal anti-HIV drug delivery, Antivir. Res. 100 (Suppl) (2013) S9-16.

[21] C. Ball, E. Krogstad, T. Chaowanachan, K.A. Woodrow, Drug-eluting fibers for HIV1 inhibition and contraception, PLoS One 7 (2012), e49792.

[22] N.D. Laborde, J. Leslie, E. Krogstad, N. Morar, P. Mutero, J. Etima, K. Woodrow, A. van der Straten, Perceptions of the "fabric" - an exploratory study of a novel multi-purpose technology among women in sub Saharan Africa, PLoS One 13 (2018), e0204821.

[23] J. das Neves, R. Nunes, F. Rodrigues, B. Sarmento, Nanomedicine in the development of anti-HIV microbicides, Adv. Drug Deliv. Rev, 103 (2016) 57-75.

[24] M.J. Faria, R. Machado, A. Ribeiro, H. Goncalves, M.E.C.D. Real Oliveira, T. Viseu, J. das Neves, M. Lúcio, Rational development of liposomal hydrogels: A strategy for topical vaginal antiretroviral drug delivery in the context of HIV prevention, Pharmaceutics 11 (2019) 485.

[25] A. Almeida, M. Araújo, R. Novoa-Carballal, F. Andrade, H. Goncalves, R.L. Reis, M. Lúcio, S. Schwartz Jr., B. Sarmento, Novel amphiphilic chitosan micelles as carriers for hydrophobic anticancer drugs, Mater. Sci. Eng. C 112 (2020) 110920.

[26] E.J. Singh, J.R. Swartwout, S. Boss, Effects of oral contraceptives on phospholipids of human cervical mucus, Am. J. Obstet. Gynecol. 112 (1972) 285-291.

[27] M.H. AbdelHay, A.A. Gazy, R.A. Shaalan, H.K. Ashour, Simple spectrophotometric methods for determination of tenofovir fumarate and emtricitabine in bulk powder and in tablets, J. Spectrosc. 2013 (2013) 937409.

[28] M.P. Cautela, H. Moshe, A. Sosnik, B. Sarmento, J. das Neves, Composite films for vaginal delivery of tenofovir disoproxil fumarate and emtricitabine, Eur. J. Pharm. Biopharm. 138 (2019) 3-10.

[29] J. das Neves, F. Araújo, F. Andrade, M. Amiji, M.F. Bahia, B. Sarmento, Biodistribution and pharmacokinetics of dapivirine-loaded nanoparticles after vaginal delivery in mice, Pharm. Res. 31 (2014) 1834-1845.

[30] C. Cunha-Reis, A. Machado, L. Barreiros, F. Araújo, R. Nunes, V. Seabra, D. Ferreira, M.A. Segundo, B. Sarmento, J. das Neves, Nanoparticles-in-film for the combined vaginal delivery of anti-HIV microbicide drugs, J. Control. Release 243 (2016) 43-53.

[31] A. Mickova, M. Buzgo, O. Benada, M. Rampichova, Z. Fisar, E. Filova, M. Tesarova, D. Lukas, E. Amler, Core/shell nanofibers with embedded liposomes as a drug delivery system, Biomacromolecules 13 (2012) 952-962.

[32] T. Costa, A. Ribeiro, R. Machado, C. Ribeiro, S. Lanceros-Mendez, A. Cavaco-Paulo, A. Almeida, J. das Neves, M. Lúcio, T. Viseu, Polymeric electrospun fibrous dressings for topical co-delivery of acyclovir and omega-3 fatty acids, front, Bioeng. Biotechnol. 7 (2019) 390.

[33] M.S. Enayati, T. Behzad, P. Sajkiewicz, R. Bagheri, L. Ghasemi-Mobarakeh, W. Łojkowski, Z. Pahlevanneshan, M. Ahmadi, Crystallinity study of electrospun poly (vinyl alcohol) nanofibers: effect of electrospinning, filler incorporation, and heat treatment, Iran. Polym. J. 25 (2016) 647-659.

[34] C.-J. Wu, J.-Z. You, X.-J. Wang, Thermal decomposition mechanism of tenofovir disoproxil fumarate, J. Therm. Anal Calorim. 132 (2018) 471-482.

[35] X.-J. Wang, J.-Z. You, F. Yu, Study on the thermal decomposition of emtricitabine, J. Anal. Appl. Pyrolysis 115 (2015) 344-352.

[36] M. Yeo, W.-K. Jung, G. Kim, Fabrication, characterisation and biological activity of phlorotannin-conjugated PCL/ $\beta$-TCP composite scaffolds for bone tissue regeneration, J. Mater. Chem. 22 (2012) 3568-3577.

[37] Y. Qian, Z. Zhang, L. Zheng, R. Song, Y. Zhao, Fabrication and characterization of electrospun polycaprolactone blended with chitosan-gelatin complex nanofibrous mats, J. Nanomater. 2014 (2014) 964621.

[38] E.M. Abdel Bary, Y.A. Soliman, A. Fekri, A.N. Harmal, Aging of novel membranes made of PVA and cellulose nanocrystals extracted from Egyptian rice husk manufactured by compression moulding process, Int. J. Environ. Stud. 75 (2018) $750-762$.

[39] A. Akil, M.A. Parniak, C.S. Dezzutti, B.J. Moncla, M.R. Cost, M. Li, L.C. Rohan, Development and characterization of a vaginal film containing dapivirine, a nonnucleoside reverse transcriptase inhibitor (NNRTI), for prevention of HIV-1 sexual transmission, Drug Deliv. Transl. Res. 1 (2011) 209-222.

[40] J. das Neves, R. Sverdlov Arzi, A. Sosnik, Molecular and cellular cues governing nanomaterial-mucosae interactions: from nanomedicine to nanotoxicology, Chem. Soc. Rev. 49 (2020) 5058-5100.

[41] Z. Abid, M. Dalskov Mosgaard, G. Manfroni, R. Singh Petersen, L. Hagner Nielsen, A. Mullertz, A. Boisen, S. Sylvest Keller, Investigation of mucoadhesion and degradation of PCL and PLGA microcontainers for oral drug delivery, Polymers 11 (2019) 1828 .

[42] G.L. Pérez-Gonzaléz, L.J. Villarreal-Gómez, A. Serrano-Medina, E.J. TorresMartínez, J.M. Cornejo-Bravo, Mucoadhesive electrospun nanofibers for drug delivery systems: applications of polymers and the parameters' roles, Int. J. Nanomedicine 14 (2019) 5271-5285.

[43] N.K. Mongia, K.S. Anseth, N.A. Peppas, Mucoadhesive poly(vinyl alcohol) hydrogels produced by freezing/thawing processes: applications in the development of wound healing systems, J. Biomater. Sci. Polym. Ed. 7 (1996) 1055-1064.

[44] N.A. Peppas, N.K. Mongia, Ultrapure poly (vinyl alcohol) hydrogels with mucoadhesive drug delivery characteristics, Eur. J. Pharm. Biopharm. 43 (1997) $51-58$. 
[45] S. Rossi, B. Vigani, G. Sandri, M.C. Bonferoni, C.M. Caramella, F. Ferrari, Recent advances in the mucus-interacting approach for vaginal drug delivery: from mucoadhesive to mucus-penetrating nanoparticles, Expert Opin. Drug Deliv. 16 (2019) 777-781.

[46] R. Sharma, T. Garg, A.K. Goyal, G. Rath, Development, optimization and evaluation of polymeric electrospun nanofiber: a tool for local delivery of fluconazole for management of vaginal candidiasis, Artif. Cells Nanomed. Biotechnol. 44 (2016) 524-531.

[47] E.A. Krogstad, R. Ramanathan, C. Nhan, J.C. Kraft, A.K. Blakney, S. Cao, R.J.Y. Ho, K.A. Woodrow, Nanoparticle-releasing nanofiber composites for enhanced in vivo vaginal retention, Biomaterials 144 (2017) 1-16.

[48] A. Popov, E. Enlow, J. Bourassa, H. Chen, Mucus-penetrating nanoparticles made with "mucoadhesive" poly(vinyl alcohol), Nanomedicine 12 (2016) 1863-1871.

[49] B. Menchicchi, J.P. Fuenzalida, A. Hensel, M.J. Swamy, L. David, C. Rochas, F. M. Goycoolea, Biophysical analysis of the molecular interactions between polysaccharides and mucin, Biomacromolecules 16 (2015) 924-935.

[50] J. das Neves, M.H. Amaral, M.F. Bahia, Performance of an in vitro mucoadhesion testing method for vaginal semisolids: Influence of different testing conditions and instrumental parameters, Eur. J. Pharm. Biopharm. 69 (2008) 622-632.

[51] K.M. Tyo, H.R. Vuong, D.A. Malik, L.B. Sims, H. Alatassi, J. Duan, W.H. Watson, J. M. Steinbach-Rankins, Multipurpose tenofovir disoproxil fumarate electrospun fibers for the prevention of HIV-1 and HSV-2 infections in vitro, Int. J. Pharm. 531 (2017) 118-133.

[52] K.M. Gallagher, O.I. Corrigan, Mechanistic aspects of the release of levamisole hydrochloride from biodegradable polymers, J. Control. Release 69 (2000) 261-272.

[53] A.K. Blakney, E.A. Krogstad, Y.H. Jiang, K.A. Woodrow, Delivery of multipurpose prevention drug combinations from electrospun nanofibers using composite microarchitectures, Int. J. Nanomedicine 9 (2014) 2967-2978.

[54] K.M. Tyo, A.B. Lasnik, L. Zhang, M. Mahmoud, A.B. Jenson, J.L. Fuqua, K. E. Palmer, J.M. Steinbach-Rankins, Sustained-release Griffithsin nanoparticle-fiber composites against HIV-1 and HSV-2 infections, J. Control. Release 321 (2020) 84-99.

[55] International Organization for Standardization, ISO 10993-5:2009 Biological Evaluation of Medical Devices - Part 5: Tests for in Vitro Cytotoxicity, 2009. Geneva, Switzerland.

[56] Center for Drug Evaluation and Research, Guidance for Industry. Estimating the Maximum Safe Starting Dose in Initial Clinical Trials for Therapeutics in Adult Healthy Volunteers, FDA, Rockville, MD, USA, 2005.

[57] M. Veselinovic, K.H. Yang, J. LeCureux, C. Sykes, L. Remling-Mulder, A. D. Kashuba, R. Akkina, HIV pre-exposure prophylaxis: mucosal tissue drug distribution of RT inhibitor Tenofovir and entry inhibitor Maraviroc in a humanized mouse model, Virology 464-465 (2014) 253-263.

[58] C.E. Henry, Y.Y. Wang, Q. Yang, T. Hoang, S. Chattopadhyay, T. Hoen, L. M. Ensign, K.L. Nunn, H. Schroeder, J. McCallen, T. Moench, R. Cone, S.R. Roffler, S.K. Lai, Anti-PEG antibodies alter the mobility and biodistribution of densely PEGylated nanoparticles in mucus, Acta Biomater. 43 (2016) 61-70.
[59] E. Taneva, K. Crooker, S.H. Park, J.T. Su, A. Ott, N. Cheshenko, I. Szleifer, P. F. Kiser, B. Frank, P.M. Mesquita, B.C. Herold, Differential mechanisms of tenofovir and tenofovir disoproxil fumarate cellular transport and implications for topical preexposure prophylaxis, Antimicrob. Agents Chemother. 60 (2015) 1667-1675.

[60] T. Zhou, M. Hu, M. Cost, S. Poloyac, L. Rohan, Expression of transporters and metabolizing enzymes in the female lower genital tract: implications for microbicide research, AIDS Res. Hum. Retrovir. 29 (2013) 1496-1503.

[61] M. Hu, S.K. Patel, T. Zhou, L.C. Rohan, Drug transporters in tissues and cells relevant to sexual transmission of HIV: implications for drug delivery, J. Control. Release 219 (2015) 681-696.

[62] T. Zhou, M. Hu, A. Pearlman, L.C. Rohan, Expression, regulation, and function of drug transporters in cervicovaginal tissues of a mouse model used for microbicide testing, Biochem. Pharmacol. 116 (2016) 162-175.

[63] J.M. Baeten, C.W. Hendrix, S.L. Hillier, Topical microbicides in HIV prevention: state of the promise, Annu. Rev. Med. (2019), https://doi.org/10.1146/annurevmed-090518-093731.

[64] H.H. Ng, H. Stock, L. Rausch, D. Bunin, A. Wang, S. Brill, J. Gow, J.C. Mirsalis, Tenofovir disoproxil fumarate: toxicity, toxicokinetics, and toxicogenomics analysis after 13 weeks of oral administration in mice, Int. J. Toxicol. 34 (2015) 4-10.

[65] B.P. Kearney, J.F. Flaherty, J. Shah, Tenofovir disoproxil fumarate: clinical pharmacology and pharmacokinetics, Clin. Pharmacokinet. 43 (2004) 595-612.

[66] P.W. Denton, J.V. Garcia, Mucosal HIV-1 transmission and prevention strategies in BLT humanized mice, Trends Microbiol. 20 (2012) 268-274.

[67] P.L. Anderson, J.J. Kiser, E.M. Gardner, J.E. Rower, A. Meditz, R.M. Grant, Pharmacological considerations for tenofovir and emtricitabine to prevent HIV infection, J. Antimicrob. Chemother. 66 (2011) 240-250.

[68] M.T.C. Mc Crudden, E. Larraneta, A. Clark, C. Jarrahian, A. Rein-Weston, B. Creelman, Y. Moyo, S. Lachau-Durand, N. Niemeijer, P. Williams, H. O. McCarthy, D. Zehrung, R.F. Donnelly, Design, formulation, and evaluation of novel dissolving microarray patches containing rilpivirine for intravaginal delivery, Adv. Healthc. Mater. 8 (2019), e1801510.

[69] F.P. Pons-Faudoa, A. Sizovs, K.A. Shelton, Z. Momin, J.A. Niles, L.R. Bushman, J. Xu, C.Y.X. Chua, J.E. Nichols, S. Demaria, M.M. Ittmann, T. Hawkins, J. F. Rooney, M.A. Marzinke, J.T. Kimata, P.L. Anderson, P.N. Nehete, R.C. Arduino, M. Ferrari, K.J. Sastry, A. Grattoni, Preventive efficacy of a tenofovir alafenamide fumarate nanofluidic implant in SHIV-challenged nonhuman primates, Adv. Ther. 2000163 (2020).

[70] L.M. Johnson, S.A. Krovi, L. Li, N. Girouard, Z.R. Demkovich, D. Myers, B. Creelman, A. van der Straten, Characterization of a reservoir-style implant for sustained release of tenofovir alafenamide (TAF) for HIV pre-exposure prophylaxis (PrEP), Pharmaceutics 11 (2019) 315.

[71] D.K. Ho, C. LeGuyader, S. Srinivasan, D. Roy, V. Vlaskin, T.E.J. Chavas, C.L. Lopez, J.M. Snyder, A. Postma, J. Chiefari, P.S. Stayton, Fully synthetic injectable depots with high drug content and tunable pharmacokinetics for long-acting drug delivery, J. Control. Release 329 (2021) 257-269. 